\title{
Proposal of a simplified criterion to estimate second order global effects in reinforced concrete buildings
}

\section{Proposta de critério simplificado para estimar efeitos de segunda ordem em edifícios de concreto armado}
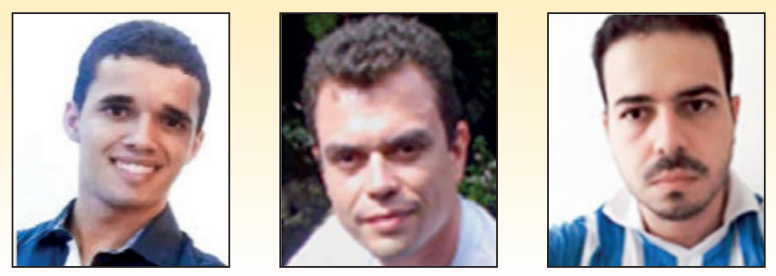

R. N. CUNHA rafaelnunes1996ufs@gmail.com https://orcid.org/0000-0003-2503-6758

L. A. MENDES a lamendes@ufs.br https://orcid.org/0000-0002-8202-7623

D. L. N. F. AMORIM a david.amorim@ufs.br https://orcid.org/0000-0002-9233-3114

\section{Abstract}

This work proposes a new simplified parameter for the calculation of second order global effects, based on the Galerkin's Method by Weighted Residuals. The proposed criterion was analysed based on 21 planar frames associated with shear wall, reaching results that present satisfactory accuracy compared to the second order global analysis, even for cases where the $\gamma_{z}$ coefficient is greater than 1.30 .

Keywords: second order global effects, reinforced concrete, weighted residuals, Galerkin's method.

\section{Resumo}

Neste trabalho propõe-se um novo parâmetro simplificado para o cálculo dos efeitos globais de segunda ordem, a partir do Método de Galerkin via Resíduos Ponderados. O critério proposto foi analisado com base em 21 pórticos planos associados a pilar-parede, alcançando resultados que apresentam acurácia satisfatória com relação à análise global de segunda ordem, mesmo para os casos em que o coeficiente $\gamma_{z}$ é superior a 1,30 .

Palavras-chave: efeitos globais de segunda ordem, concreto armado, resíduos ponderados, método de Galerkin.

Federal University of Sergipe, Post-Graduation Program in Civil Engineering, Mathematical Modelling Laboratory in Civil Engineering, São Cristóvão, SE, Brasil. Received: 05 Aug 2019 • Accepted: 30 Sep 2019 • Available Online: 26 Mar 2020 


\section{Introduction}

NBR 6118 [1] allows that second global effects may be estimated in a simplified way by the instability parameter $\alpha$ and the $\gamma_{z}$ coefficient. The instability parameter $\alpha$ is obtained from the solution of an ordinary differential equation using Bessel's functions [2]. However, this parameter can only be used to verify the necessity to take into account second global effects. On the other hand, the coefficient $\gamma_{z}$ was originally obtained from a geometric progression considering that the convergence is obtained with several steps [3]. Therefore, with the $\gamma_{z}$ coefficient it is possible to estimate the second order global effects using only a first order analysis. Nevertheless, NBR 6118 [1] requires that $1.10<\gamma_{z} \leq 1.30$ for the second order global effects be estimated satisfactorily by increasing the horizontal actions by $0.95 \gamma_{z}$ in a new first order analysis. In the light of the foregoing, this paper presents an alternative form to quantify the second order global effects, also in a simplified way, by using a procedure based on the Galerkin's Method in its approach by Weighted Residuals. The proposed parameter has an analogous applicability to $\gamma_{z}$ coefficient i.e. the second order global effects can be estimated through a first order analysis by increasing the horizontal forces.

\section{Galerkin's method by weighted residuals}

\subsection{Simplified strong form}

For the sake of simplicity, consider that a building can be represented by a vertical bar of length $L$ with axial $p$ and transversa q distributed loads, as illustrated in Figure 1. Assuming the axial stiffness of the bar (AE) is high, the axial displacement field can be described by equation (1).

$u(x)=-\frac{p L^{2}}{2 A E}\left[\frac{2 x}{L}-\left(\frac{x}{L}\right)^{2}\right]$

On other hand, it is proposed that the field of bending moments along the bar must consider second order effects [4]:

$M(x)=-E I \frac{d^{2} v(x)}{d x^{2}}+A E\left[\frac{d u(x)}{d x}+\frac{1}{2}\left(\frac{d v(x)}{d x}\right)^{2}\right] v(x)$

where, $\mathrm{El}$ is the flexural stiffness of the bar and $\mathrm{v}(\mathrm{x})$ is the transversal displacements field. Since $d^{2} M / d x^{2}=-q$, then:

$-E I \frac{d^{4} v(x)}{d x^{4}}+A E v(x)\left(\frac{d^{2} v(x)}{d x^{2}}\right)^{2}+A E v(x) \frac{d v(x)}{d x} \frac{d^{3} v(x)}{d x^{3}}+2 p \frac{d v(x)}{d x}$

$+2 A E \frac{d v(x)}{d x^{2}}\left(\frac{d v(x)}{d x}\right)^{2}-p L\left(1-\frac{x}{L^{2}}\right) \frac{d^{2} v(x)}{d x^{2}} i$

$+\frac{1}{2} A E \frac{d^{2} v(x)}{d x^{2}}\left(\frac{d v(x)}{d x}\right)^{2}=-q$

In order to avoid the use of an iterative incremental procedure, given its low viability in simplified design procedures, a direct simplification of equation (3) is proposed by eliminating the terms that depend on $v(x)$ or its derivatives more than one time, obtaining the equation (4).

$-E I \frac{d^{4} v(x)}{d x^{4}}+2 p \frac{d v(x)}{d x}-p L\left(1-\frac{x}{L^{2}}\right) \frac{d^{2} v(x)}{d x^{2}}=-q$
Note that, this simplification results in loss of accuracy in the equation that governs the problem (4), because many of the terms that quantify the second order global effects have been excluded. However, a correction factor is introduced in the proposed parameter to compensate the eliminated terms (see section 3).

\subsection{Weak form}

The weak form of the problem is obtained using the equation (4) to define the residual function $R(x)$, which must be minimised along the problem domain:

$\int_{0}^{L} R(x) \omega(x) d x=0 \quad \forall \omega(x)$

$\therefore R(x)=q-E I \frac{d^{4} v(x)}{d x^{4}}+2 p \frac{d v(x)}{d x}-p L\left(1-\frac{x}{L^{2}}\right) \frac{d^{2} v(x)}{d x^{2}}$

where $\mathrm{v}(\mathrm{x})$ obeys the boundary conditions of the problem and $\mathrm{e} \omega(\mathrm{x})$ must be continuous and homogeneous in the essential boundary conditions [5].

The field of transversal displacements, in index notation, is approximated by:

$v(x)=\alpha_{i} \phi_{i}(x) \quad\{i=1, \ldots, n\}$

where $\alpha_{i}$ are the constants to be determined, $\phi_{i}(x)$ are the adopted functions and $n$ is the number of approximation terms of $v(x)$.

The Galerkin's method for residual weighted proposes the adoption of the weight function given in (7).

$\omega(x)=\beta_{j} \phi_{j}(x) \quad\{j=1, \ldots, n\}$

Being $\beta_{\mathrm{i}}$ the constants of the function $\omega(\mathrm{x})$.

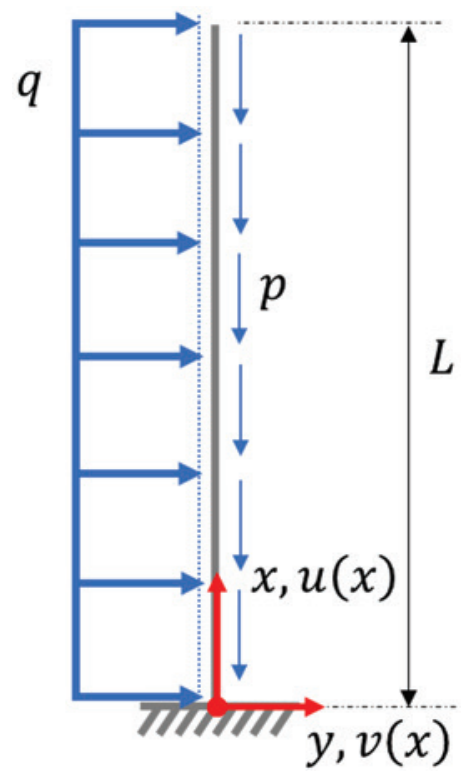

Figure 1

Vertical bar 


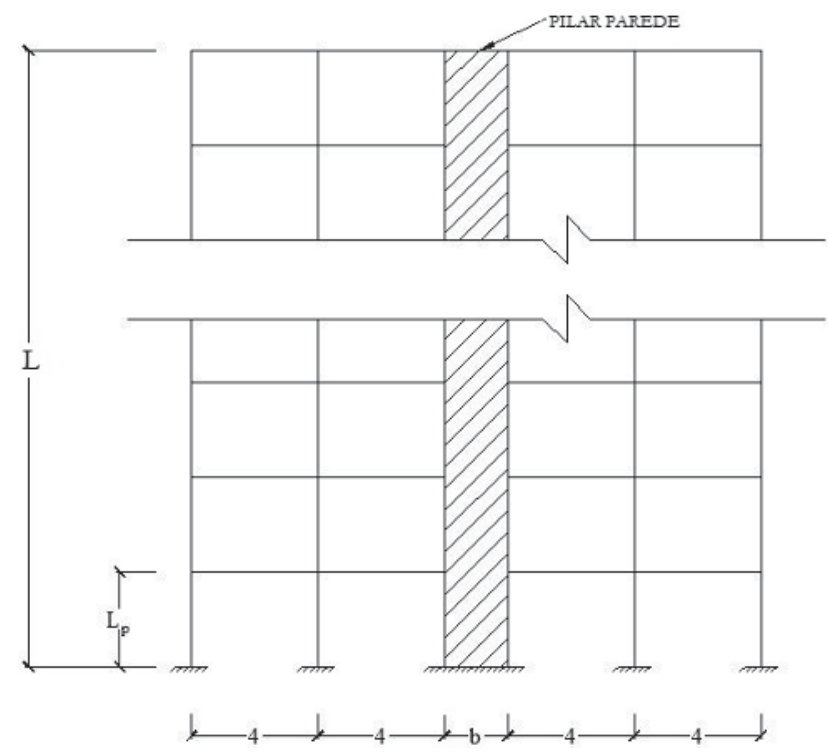

(a)

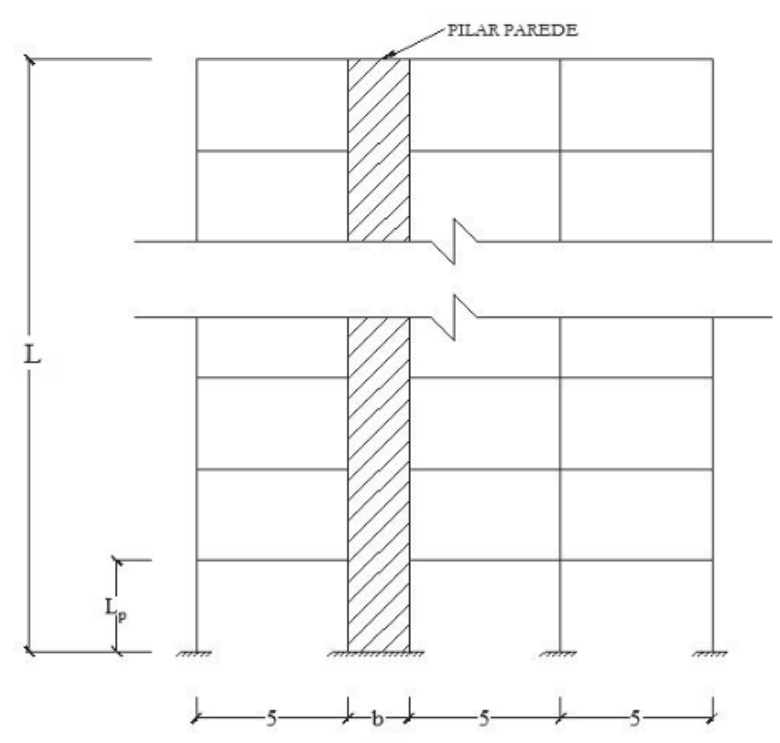

(b)

\section{Figure 2}

Model of planar frame 1 (a) and model of planar frame 2 (b)

By substituting (6) and (7) in (5), for any $\beta_{\mathrm{j}}$, the following matrix relation is obtained:

$\mathbf{K}^{\mathrm{T}} \boldsymbol{\alpha}=\mathbf{F} . \therefore\left\{\begin{array}{c}K_{i j}=\int_{0}^{L}\left[E I \frac{\partial^{4} \phi_{i}(x)}{\partial x^{4}} \phi_{j}(x)+2 p \frac{\partial \phi_{i}(x)}{\partial x} \phi_{j}(x)-p L\left(1-\frac{x}{L^{2}}\right) \frac{\partial^{2} \phi_{i}(x)}{\partial x^{2}} \phi_{j}(x)\right] d x \\ F_{j}=\int_{0}^{L} q \phi_{j}(x) d x\end{array}\right.$

\section{Proposed simplified criterion $\left(\zeta_{g}\right)$}

Since the $\gamma_{z}$ coefficient was deduced as the direct ratio between the second order effects and the first order effects (moments), this paper proposes a similar coefficient i.e.:

$\zeta_{g}=\kappa \frac{M_{2}}{M_{1}}$

where $\zeta_{\mathrm{g}}$ is the coefficient proposed in this paper, $\mathrm{M}_{1}$ is the first order moment, given in Figure $1, \mathrm{M}_{2}$ is the second order moment and $\kappa$ is a dimensionless parameter introduced to compensate the eliminated terms of the equation (3) and, therefore, to approximate the results of the displacements of the structure with the reference results.

To solve equation (4), a complete fourth degree polynomial approximation was used and $\mathrm{M}_{2}$ was obtained from the solution of the field of transversal displacements together with the relation $M=-E l d^{2} v(x) / d x^{2}$, given by equation (10).

$M_{2}=\frac{-108 E I q L^{2}\left[-21 L^{9} p^{3}+8215 E L_{L}^{6} p^{2}-638550(E I)^{2} L^{3} p+9147600(E I)^{3}\right]}{259 L^{12} p^{4}-140352 E I L^{9} p^{3}+18993312(E I)^{2} L^{6} p^{2}-632681280(E I)^{3} L^{3} p+1975881600(E I)^{4}}$

For the application of equation (10) in any frame, $L$ is the total height of the building, $p$ is the sum of all vertical loads distributed along the height $\mathrm{L}$ and $\mathrm{El}$ is the equivalent stiffness of the frame.

\section{Results and discussions}

Twenty-one planar frames with bracing system composed by the association between planar frames and shear-wall were analysed

Table 1

Resume of planar frames analyzed

\begin{tabular}{cccc}
\hline Planar frame & Model & $\begin{array}{c}\text { L } \\
{[\mathbf{m}]}\end{array}$ & $\begin{array}{c}\text { Shear wall }(\mathbf{b} \\
\mathbf{\times} \text { h) }\end{array}$ \\
\hline 1 & 1 & 48 & $4.00 \times 0.20$ \\
2 & 2 & 24 & $1.50 \times 0.25$ \\
3 & 2 & 30 & $1.50 \times 0.25$ \\
4 & 1 & 54 & $4.00 \times 0.20$ \\
5 & 1 & 51 & $4.00 \times 0.20$ \\
6 & 2 & 36 & $2.00 \times 0.25$ \\
7 & 2 & 42 & $2.00 \times 0.25$ \\
8 & 1 & 66 & $4.00 \times 0.20$ \\
9 & 1 & 75 & $4.00 \times 0.20$ \\
10 & 1 & 81 & $4.00 \times 0.20$ \\
11 & 1 & 78 & $4.00 \times 0.20$ \\
12 & 1 & 84 & $4.00 \times 0.20$ \\
13 & 2 & 39 & $2.00 \times 0.25$ \\
14 & 1 & 69 & $4.00 \times 0.20$ \\
15 & 1 & 78 & $4.00 \times 0.25$ \\
16 & 1 & 81 & $4.00 \times 0.25$ \\
17 & 1 & 84 & $4.00 \times 0.25$ \\
18 & 1 & 81 & $4.00 \times 0.29$ \\
19 & 1 & 84 & $4.00 \times 0.30$ \\
20 & 1 & 87 & $4.00 \times 0.30$ \\
21 & 1 & 78 & $4.00 \times 0.23$ \\
\hline
\end{tabular}



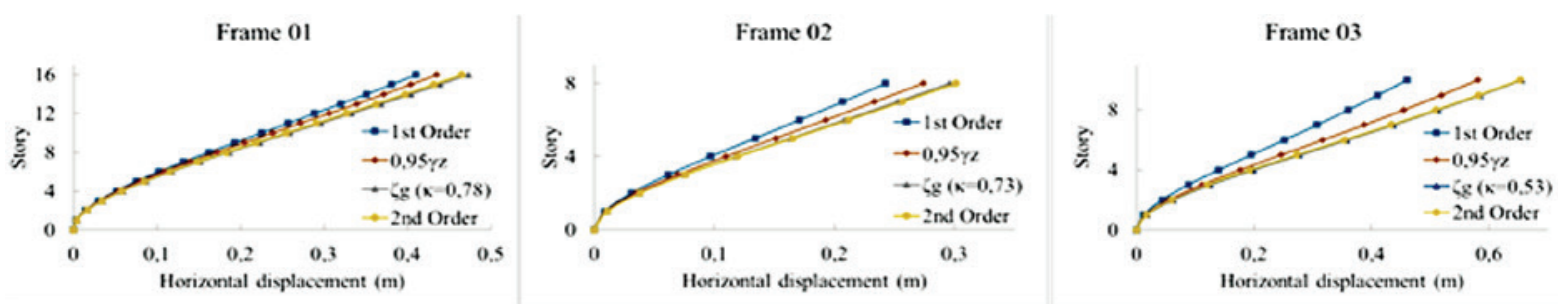

Frame 04

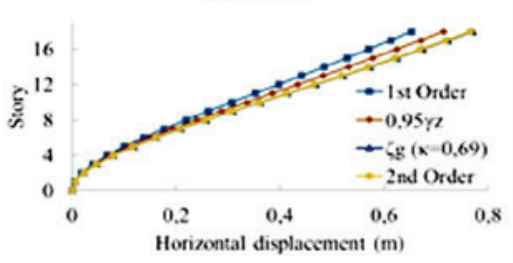

Frame 05

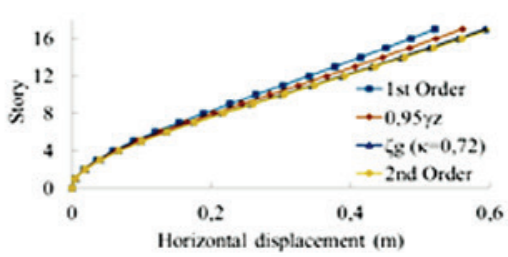

Frame 06

Frame 07

Frame 08
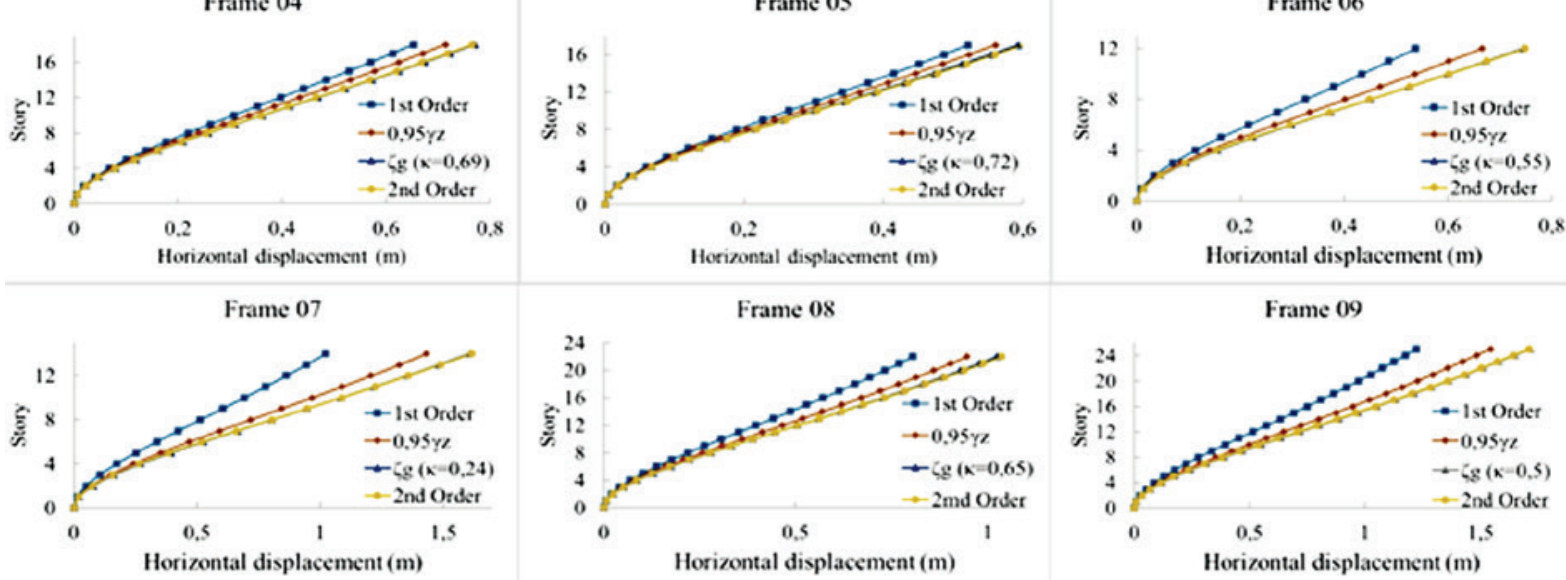

Frame 10
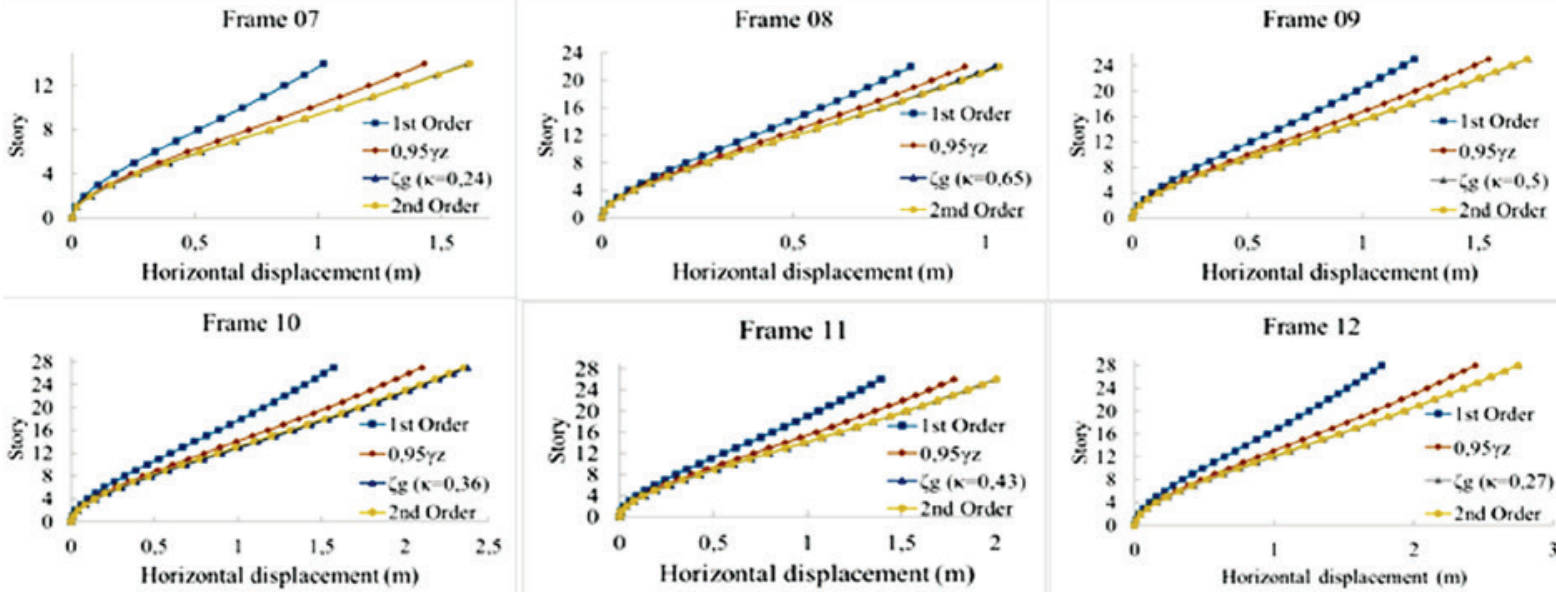

Frame 13

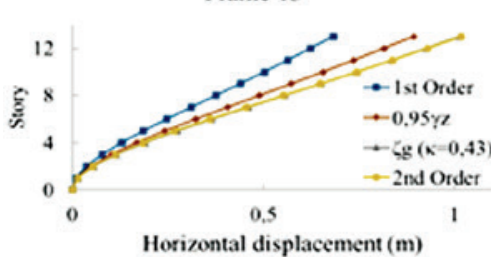

Frame 14
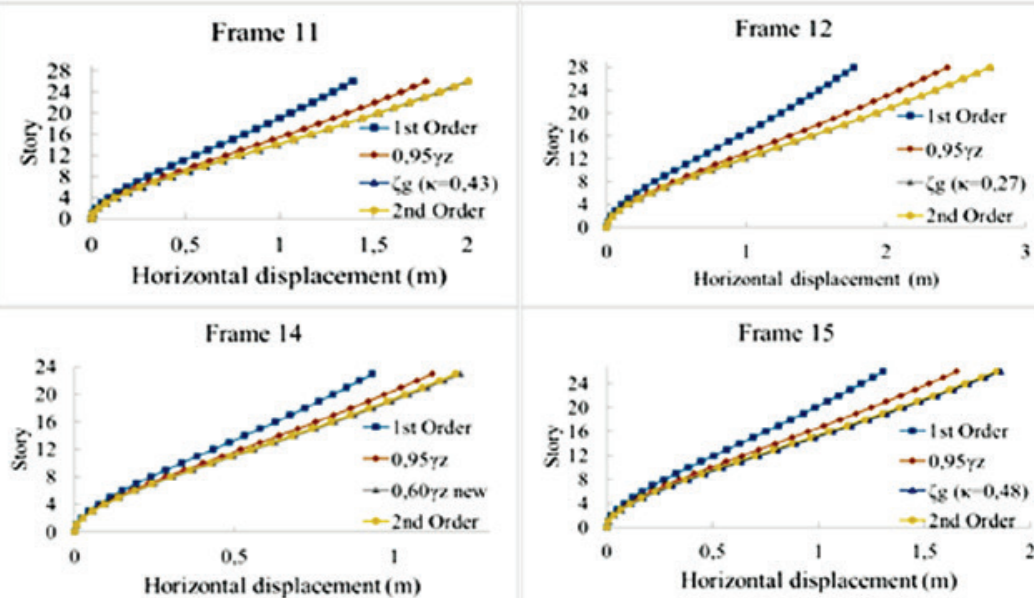

Frame 15
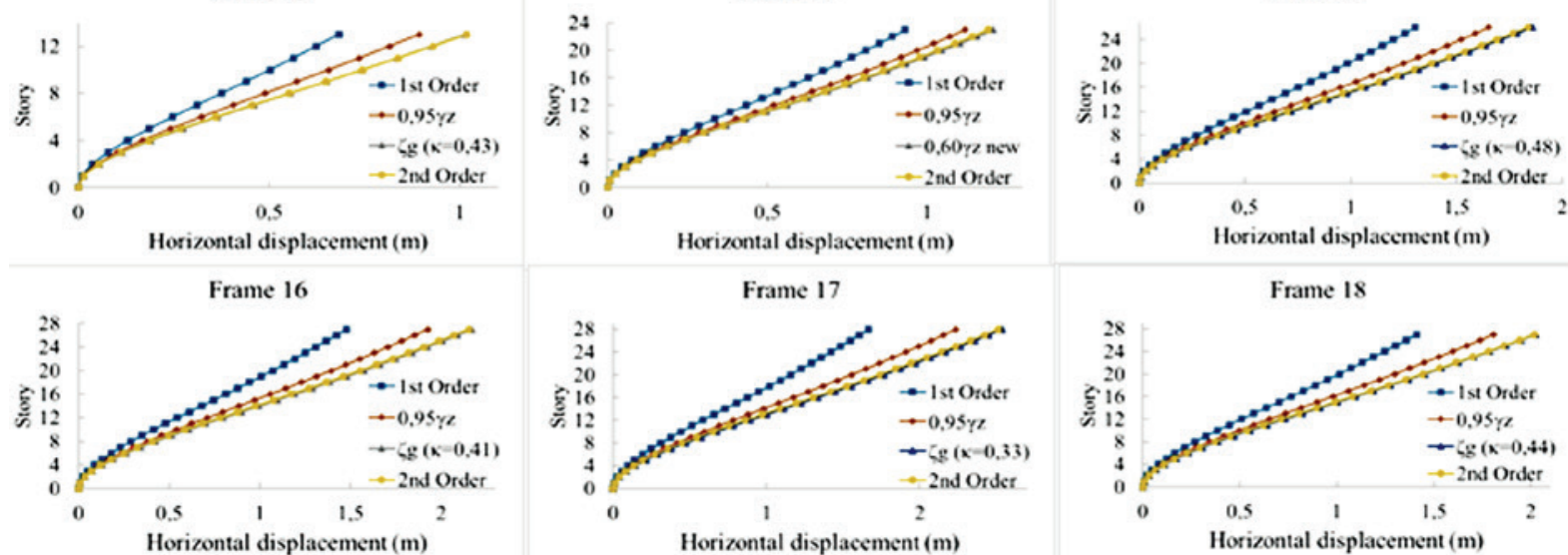

Frame 19
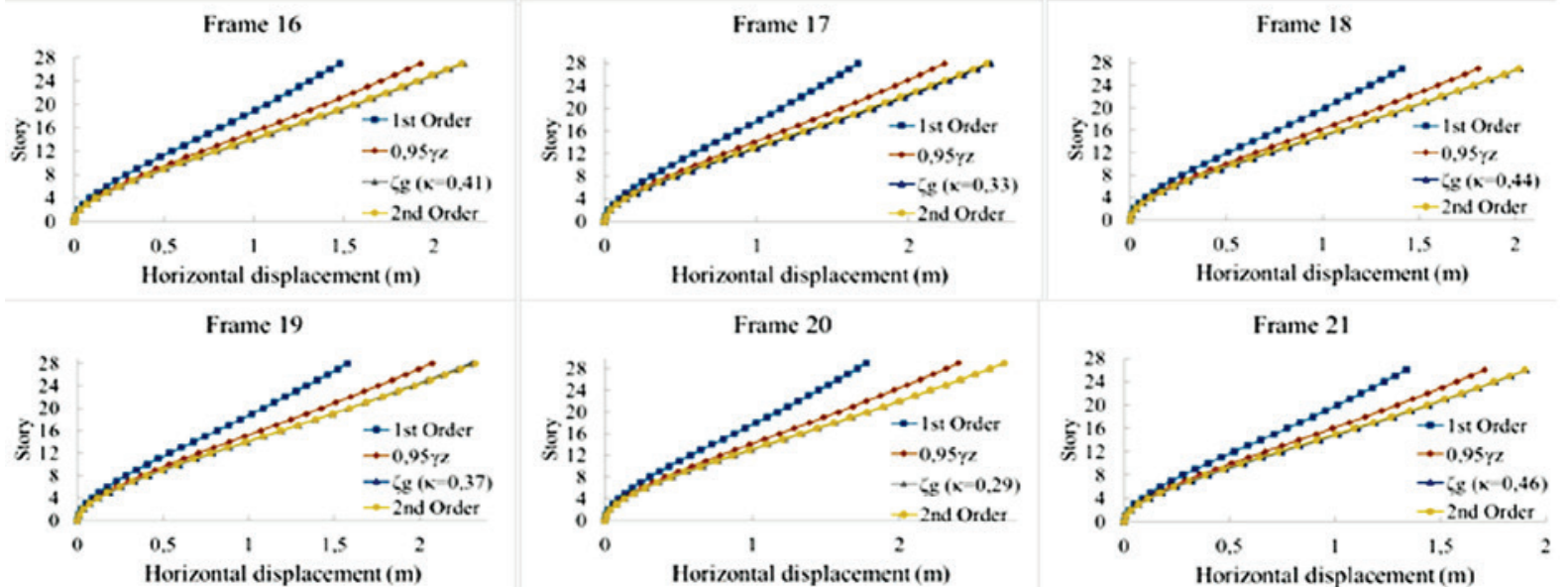

\section{Figure 3}

Results of the analysed planar frames 
Table 2

Resume of $\gamma_{z^{\prime}} M_{2} / M_{1}, \kappa$ and calculation of NSE

\begin{tabular}{ccccc}
\hline $\begin{array}{c}\text { Planar } \\
\text { frame }\end{array}$ & $\gamma_{z}$ & $\mathbf{M}_{\mathbf{2}} / \mathbf{M}_{1}$ & $\kappa_{\mathrm{o}}$ & $\kappa_{\mathrm{p}}$ \\
\hline 1 & 1.12 & 1.48 & 0.78 & 0.77 \\
2 & 1.19 & 1.67 & 0.73 & 0.71 \\
3 & 1.32 & 2.67 & 0.53 & 0.52 \\
4 & 1.15 & 1.71 & 0.69 & 0.70 \\
5 & 1.13 & 1.58 & 0.72 & 0.74 \\
6 & 1.29 & 2.49 & 0.55 & 0.54 \\
7 & 1.46 & 6.46 & 0.24 & 0.24 \\
8 & 1.24 & 1.96 & 0.65 & 0.64 \\
9 & 1.33 & 2.81 & 0.50 & 0.50 \\
10 & 1.41 & 4.20 & 0.36 & 0.36 \\
11 & 1.37 & 3.34 & 0.43 & 0.43 \\
12 & 1.45 & 5.75 & 0.27 & 0.27 \\
13 & 1.36 & 3.40 & 0.43 & 0.43 \\
14 & 1.26 & 2.16 & 0.59 & 0.60 \\
15 & 1.33 & 2.96 & 0.48 & 0.48 \\
16 & 1.37 & 3.58 & 0.41 & 0.41 \\
17 & 1.41 & 4.62 & 0.33 & 0.33 \\
18 & 1.35 & 3.26 & 0.44 & 0.44 \\
19 & 1.38 & 3.95 & 0.37 & 0.38 \\
20 & 1.42 & 5.26 & 0.29 & 0.29 \\
21 & 1.35 & 3.10 & 0.46 & 0.46 \\
\hline & & & $N S E$ & 0.997 \\
\hline & & & &
\end{tabular}

in this paper (Figure 2). In such examples, the obtained results with the proposed $\zeta_{\mathrm{g}}$ coefficient are compared to the ones obtained with $\gamma_{z}$ coefficient [1] and with first and second order analyses. The planar frames were simulated in MASTAN2 software by using the prediction-correction algorithm [6]. The effects of reinforced concrete physical nonlinearity were considered in a simplified way, according to item 15.7.3 of NBR 6118 [1].

Note that for the analysed frames the value of $\mathrm{K}$ was adopted to ensure that the horizontal displacements obtained with $\zeta_{g}$ are quite close to the second order displacement results of the structure. Thus, Table 1 brings brief information of all analysed planar frames, where the height of each story $\left(L_{p}\right)$ is $3 \mathrm{~m}$ and the horizontal loads were calculated based on NBR 6123 [7], for a basic velocity of $40 \mathrm{~m} / \mathrm{s}$ and with the following coefficients:

$S_{1}=1$

$S_{2}=\left\{\begin{array}{c}0.6374 z^{0.125} \text { if } \mathrm{L}<50 \mathrm{~m} \\ 0.6156 \mathrm{z}^{0.135} \text { if } \mathrm{L} \geq 50 \mathrm{~m}\end{array}\right.$

$S_{3}=1$

where $\mathrm{z}$ is the height of analysed story.

Figure 3 shows the results of horizontal displacements per story for the analysed frames.

From Figure 3 were selected the $\kappa$ coefficients that best fit the curve of the second order analysis and then it was possible to obtain the Table 2, showing the relation between $\gamma_{z}, M_{2} / M_{1}$ and $\kappa$.

Nonlinear correlation analyses between the ratio $M_{2} / M_{1}$ and $\kappa$ were performed based on Table 2 by using the Past! software [8]. Therefore, the equation that presents the best adjustment is given in (12).
$\kappa=-0.3864+1.3644\left(\frac{M_{2}}{M_{1}}\right)^{-0.4205}$

Figure 4 shows the adjust of the equation (12) with 95\% confidence interval performed in the Past! software based on values of $\mathrm{M}_{2} / \mathrm{M}_{1}$ and $\mathrm{K}$ from Table 2.

It is noteworthy that part of the examples solved by the proposed criterion $\left(\zeta_{g}\right)$ reached values of $\gamma_{z}$ higher than 1.30 , which is the upper limit given on NBR 6118 [1]. The average relative error for the horizontal displacement using the proposed parameter, in relation to second order analysis, was considered satisfactory, because it is equal to $1.98 \%$, while the same error using the $\gamma_{z}$ coefficient is $-8.15 \%$ considering all frames and $-6.93 \%$ considering only the frames with $\gamma_{\mathrm{z}} \leq 1.30$.

Furthermore, in order to verify the quality of the proposed nonlinear adjust (12), the Nash-Sutcliffe coefficient [9] was chosen, given by equation (13)

$N S E=1-\frac{\sum_{t=1}^{n}\left(\kappa_{p}^{t}-\kappa_{o}^{t}\right)^{2}}{\sum_{t=1}^{n}\left(\kappa_{o}^{t}-\kappa_{o}^{A v g}\right)^{2}}$

Where $\kappa_{p}^{t}$ is the predicted coefficient by equation (12), $\kappa_{o}^{t}$ is the observed coefficient and $\kappa_{o}^{A v g}$ is the average of the observed coefficients. According to [9], the Nash-Sutcliffe coefficient determines the magnitude of the residual variance in relation to the observed data variance, assuming values in the range $-\infty<\mathrm{NSE} \leq 1$. The unitary value means a perfect fit of the model. An efficiency NSE $=0$ means that the predictions of equation (12) are as accurate as the average of the observed data and NSE $<0$ indicates that the average of the observed data is a better prediction than equation (12). The Table 2 shows the calculation of the NSE, obtaining an efficiency equal to 0.997 .

\section{Conclusions}

This paper proposes a new simplified method for the analysis of the second order global effects in reinforced concrete structures through the analysis of planar frames combined with shear-wall. For the analysed examples, it was possible to observe that the results in structural displacements were more accurate than the

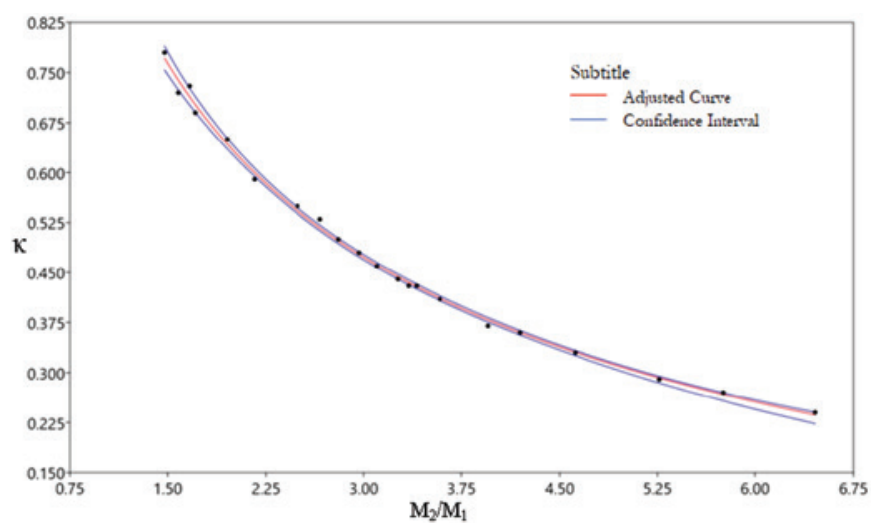

Figure 4

Adjustment between $\mathrm{M}_{2} / \mathrm{M}_{1}$ and $\kappa$ with confidence interval of $95 \%$ 
ones recommended by NBR 6118 [1], being possible to obtain an analytical equation for the parameter $\zeta_{g}$ with optimal quality, according to the Nash-Sutcliffe coefficient [9].

It is recommended that in future papers the application of the proposed procedure in this paper for more planar frames combined with shear-wall, as well as structures whose bracing system consists only by planar frames. Notwithstanding, studies in three-dimensional models are also necessary to evaluate the accuracy of the proposed procedure.

Finally, if properly tested, this procedure may be applied to other types of structures, such as steel and masonry buildings.

\section{Acknowledgements}

The authors would like to thank to Mathematical Modelling Laboratory in Civil Engineering, which is managed by the Post-Graduation Program in Civil Engineering of the Federal University of Sergipe, by the physical support.

\section{References}

[1] ASSOCIAÇÃO BRASILEIRA DE NORMAS TÉCNICAS. Projeto de estruturas de concreto armado - procedimento. - NBR 6118, Rio de Janeiro, 2014.

[2] BECK, H.; KÖNIG, G. Restraining forces in the analysis of tall buildings. In: Symposium on Tall Buildings, Oxford, 1966, Proceedings, Pergamon Press, Oxford, 1966.

[3] FRANCO, M.; VASCONCELOS, A. C. Practical assessment of second order effects in tall buildings. In: COLLOQUIUM ON THE CEB-FIP MC90, Rio de Janeiro, 1991, Proceedings, Rio de Janeiro, 1991. p. 307-324.

[4] POWELL, G. H. Theory of nonlinear elastic structures. Journal of the Structural Division (ASCE), ST12, 1969, p.2687-2701.

[5] PROENÇA, S. P. B. Introdução aos métodos numéricos. Notas de aula - Escola de Engenharia de São Carlos, Universidade de São Paulo, São Carlos, 2007, 145 p.

[6] MCGUIRE, W.; GALLAGHER, R. H.; ZIEMIAN, R. D. Matrix Structural Analysis, Lewisburg: Bucknell University, 2ed, 2014, $482 \mathrm{p}$.

[7] ASSOCIAÇÃO BRASILEIRA DE NORMAS TÉCNICAS. Forças devidas ao vento em edificações. - NBR 6123, Rio de Janeiro, 1988.

[8] HAMMER, Ø.; HARPER, D. A. T.; RYAN, P. D. PAST: paleontological statistics software package for education and data analysis. Palaeontologia Electronica, 2001, v. $4,9 \mathrm{p}$.

[9] NASH, J. E.; SUTCLIFFE, J. V. River flow forecasting through conceptual models part I - A discussion of principles. Journal of Hydrology, v.10, 1970, p.282-290. 